\title{
Partial iris hypoplasia in a patient with an interstitial subtelomeric $6 p$ deletion not including the forkhead transcription factor gene FOXC1
}

\author{
European Journal of Human Genetics (2005) 13, 1169-1171. doi:10.1038/sj.ejhg.5201487;
} published online 24 August 2005

We read the article: 'Cryptic subtelomeric $6 \mathrm{p}$ deletion in a girl with congenital malformations and severe language impairment ${ }^{1}$ with interest, in which Anderlid et al narrow down the critical region of the 6 pter deletion syndrome to a $2.1 \mathrm{Mb}$ genetic interval. The 6 pter deletion syndrome is associated with hearing loss, heart defects, hypertelorism, mid-face hypoplasia, low set ears, developmental delay and defects of the anterior eye-chamber development. ${ }^{2} \mathrm{We}$ present a patient with partial iris hypoplasia and an interstitial subtelomeric 6p25 deletion, which spanned approximately $200 \mathrm{~kb}$ and did not encompass the forkhead transcription factor gene FOXC1, associated with anterior eye-chamber development.

The girl was the first child of nonconsanguineous parents, who were both 26 years of age at the time of conception. There was no family history of congenital malformations or mental retardation. She was born at 37 $1 / 7$ weeks of gestation, after an uneventful pregnancy and delivery (birth weight $2235 \mathrm{~g}, 15 \mathrm{th}$ centile; length $46 \mathrm{~cm}$, 25 th centile). At the age of 5 months, she was referred to our department, because of hypotonia and multiple facial dysmorphisms. At that time her weight was $5920 \mathrm{~g}$ (10th centile), length $63 \mathrm{~cm}$ (40th centile) and occipital frontal circumference (OFC) was $39.5 \mathrm{~cm}$ (2nd centile). Dysmorphic features included brachycephaly, prominent forehead, mid-face hypoplasia, micrognathia, telecanthus, upslanting palpebral fissures, flat ear helices, small nose, broad flat nasal bridge, long philtrum, thin upper lip and a protruding tongue. In addition, she had small hands with single palmar creases and small feet with hypoplastic nails. Extensive ophthalmologic examination showed divergent strabismus, hypermetropy (ODS: $+6,+6)$ and bilateral peripheral iris stromal hypoplasia. Strabismus was surgically corrected. However, 6 months later, she developed convergent strabismus of the left eye. Cardiac examination and magnetic resonance imaging of the cerebrum showed no abnormalities. Delay in psychomotor development was prominent with initial walking at 2.5 years and a severe delay in speech development. Examination at the age of 5 years and 8 months revealed a moderately mentally retarded girl with a height of $112 \mathrm{~cm}$ (16th centile) and
OFC of $48 \mathrm{~cm}$ (5th centile). She showed dysmorphisms as described before (Figure 1), which were very similar to the case reported by Anderlid et al, ${ }^{1}$ as well as other cases reported with a distal $6 \mathrm{p}$ deletion. ${ }^{3-5}$ In addition, she had severe eczema of the left elbow and she showed autistic features. These features were also noted in the case described by Anderlid et al. ${ }^{1}$ However, in contrast to the latter case, our patient had a developmental delay. Cytogenetic studies (blood lymphocytes and fibroblasts) revealed a normal female karyotype and no fragile $\mathrm{X}$ mutation. Multiplex ligation-dependent probe amplification (MLPA) using the SALSA Human Telomere Test Kit P019/20 (MRC-Holland, Amsterdam, The Netherlands) was performed as described previously ${ }^{6}$ and showed a subtelomeric deletion at 6p25 (probe DUSP22_e6). This 6pter deletion was confirmed by fluorescent in situ hybridisation (FISH) on metaphase spreads using probes specific for the subtelomeric 6p region (GS-196-I5, GS-62-L11). ${ }^{7}$ Testing of the parents using the same MLPA and FISH probes was normal and paternity was confirmed using informative markers. Further characterisation of the deletion by array CGH (32K BAC array), microsattelite markers and MLPA probes in the distal $1.6 \mathrm{Mb}$ of the short arm of chromosome 6 revealed that the deletion was interstitial and spanned $\sim 200 \mathrm{~kb}$ (Figure 2a, b).
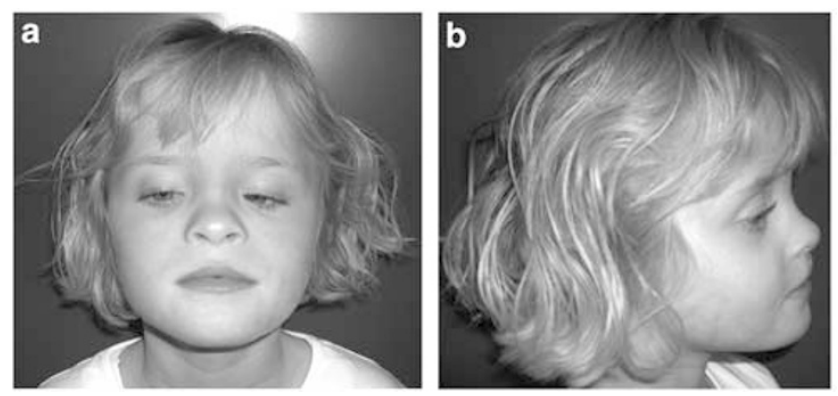

Figure 1 (a, b) Proband at 5 years and 8 months. Note brachycephaly, prominent forehead, mid-face hypoplasia, micrognathia, telecanthus, small nose, broad flat nasal bridge and a long philtrum. 

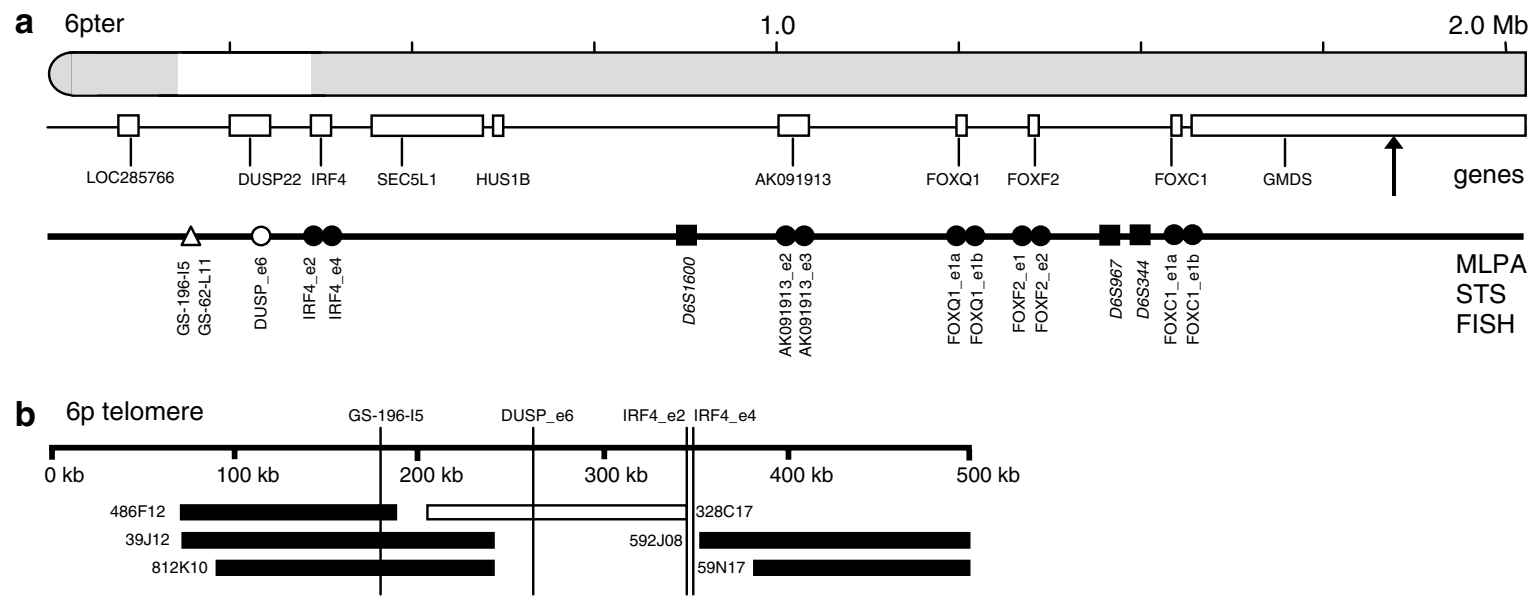

Figure 2 (a) Physical map of the $6 \mathrm{p} 25$ terminal region with the $200 \mathrm{~kb}$ interstitial deletion shown in white. The arrow indicates the deletion breakpoint described by Anderlid et al at $\sim 1.8 \mathrm{Mb}$, according to the UCSC Genome Browser on Human, May 2004 Assembly. The position of the MLPA probes, sequence-tagged-sites (STSs) and FISH clones is depicted schematically by circles, squares and triangles, respectively. These symbols are either blackened or unblackened indicating the presence or absence of the probe, marker or clone. The localisation of the FISH probes used (GS-196-I5 and GS-62-L11) is indicated by the sequence-tagged-site (STS), 6PTEL48 in the probes, as described by Knight et al. ${ }^{7}$ All MLPA probes, and the STS markers are positioned according to the UCSC Genome Browser, May 2004. (b) Array CGH results, showing the detailed positioning of the BAC clones at the $6 p$ telomere. The BAC clone RP11-328C17 (unblackened) is deleted in our patient, whereas the other clones at 6pter are present (blackened). BAC clone positions were adjusted/reassigned based on alignment of its sequence to the May 2004 release of the UCSC Genome Browser.

The facial dysmorphisms described in this girl are consistent with those found in cases with larger 6pter deletions. $^{1-5}$ Moreover, abnormalities of the anterior chamber of the eye are consistent findings in terminal $6 \mathrm{p}$ deletions. ${ }^{1}$ Both structural eye anomalies and functional abnormalities have been reported in $6 \mathrm{p}$ deletion cases, ${ }^{3}$ as was also seen in our case (strabismus, hypermetropy and stromal hypoplasia). The maximum deletion size at $6 \mathrm{p} 25$ in our patient was $\sim 200 \mathrm{~kb}$ and included the most distal $1.4 \mathrm{~kb}$ of the interferon regulatory factor 4 gene (IRF4) and the dual specificity phosphatase 22 gene (DUSP22 or MKPX) (Figure 2a, b). The deleted region mapped $\sim 1.2 \mathrm{Mb}$ distally from the forkhead transcription factor gene, FOXC1 on 6p25 (Figure 2a). FOXC1 is an important gene for normal development of the anterior chamber of the eye. Mutations in this gene have been identified in sporadic and familial patients with a diverse spectrum of ocular developmental defects with associated glaucoma, including Axenfield anomaly, Rieger anomaly, Rieger syndrome and iris hypoplasia. ${ }^{8-10}$ However, FOXC1 mutations have not been found in all familial cases linked to 6 p25 with glaucoma and anterior segment dysgenesis. It has been demonstrated that chromosomal deletions and duplications involving the FOXC1 gene cause abnormal development of the anterior segment of the eye, indicating that FOXC1 has a dosage-sensitive effect on anterior chamber development in the eye. ${ }^{11-13}$ The complex regulatory requirements of the forkhead transcription factor genes is indicated by several long-range position effects associated with this gene family (reviewed by Kleinjan and van Heyningen ${ }^{14}$ ). A position effect due to the $200 \mathrm{~kb}$ deletion, $1.2 \mathrm{Mb}$ upstream of FOXC1 might explain the eye abnormalities in our patient, as the deletion did not include the FOXC1 nor the other forkhead/winged helix genes at 6p25 (FOXF2, FOXQ1). In addition, the (milder) ocular abnormalities in our patient might also be caused by a position effect on FOXF2 that is also expressed in the developing eye. Recently, Velagaleti et $a l^{15}$ described position effects due to translocation breakpoints mapping up to $1.3 \mathrm{Mb}$ upstream of another dosage sensitive gene, SOX9 in Campomelic Dysplasia and identified a candidate cis-regulatory element. Likewise, separation of the promotor/transcription unit of FOXC1 and/or FOXF2 from an essential distant regulatory element in the $200 \mathrm{~kb}$ deleted region is one of the mechanisms that might be responsible for the phenotype in the current case, underscoring the complexity of the $6 \mathrm{p}$ subtelomeric region and the importance of long-range position effects in human genetic disease.

David A Koolen ${ }^{1}$, Nine VAM Knoers ${ }^{1}$, Willy M Nillesen ${ }^{1}$, Gordon HPR Slabbers ${ }^{2}$, Dominique Smeets ${ }^{1}$, Nicole de Leeuw $^{1}$, Erik A Sistermans ${ }^{1}$ and Bert BA de Vries ${ }^{1}$

${ }^{1}$ Department of Human Genetics, Radboud University Nijmegen Medical Centre, Nijmegen, The Netherlands;

${ }^{2}$ Department of Paediatrics, Bernhoven Hospital, Oss, The Netherlands. E-mail: b.devries@antrg.umcn.nl 


\section{References}

1 Anderlid BM, Schoumans J, Hallqvist A et al: Cryptic subtelomeric $6 \mathrm{p}$ deletion in a girl with congenital malformations and severe language impairment. Eur J Hum Genet 2003; 11: 89-92.

2 Davies AF, Mirza G, Sekhon G et al: Delineation of two distinct 6p deletion syndromes. Hum Genet 1999; 104: 64-72.

3 Law CJ, Fisher AM, Temple IK: Distal 6p deletion syndrome: a report of a case with anterior chamber eye anomaly and review of published reports. J Med Genet 1998; 35: 685-689.

4 Gould DB, Jaafar MS, Addison MK et al: Phenotypic and molecular assessment of seven patients with $6 \mathrm{p} 25$ deletion syndrome: relevance to ocular dysgenesis and hearing impairment. BMC Med Genet 2004; 5: 17.

5 Mirza G, Williams RR, Mohammed S et al: Refined genotypephenotype correlations in cases of chromosome $6 \mathrm{p}$ deletion syndromes. Eur J Hum Genet 2004; 12: 718-728.

6 Koolen DA, Vissers LE, Nillesen W et al: A novel microdeletion, $\operatorname{del}(2)(q 22.3 q 23.3)$ in a mentally retarded patient, detected by array-based comparative genomic hybridization. Clin Genet 2004; 65: $429-432$.

7 Knight SJ, Lese CM, Precht KS et al: An optimized set of human telomere clones for studying telomere integrity and architecture. Am I Hum Genet 2000; 67: 320-332.

8 Mears AJ, Jordan T, Mirzayans F et al: Mutations of the forkhead/ winged-helix gene, FKHL7, in patients with Axenfeld-Rieger anomaly. Am J Hum Genet 1998; 63: 1316-1328.
9 Mirzayans F, Gould DB, Heon E et al: Axenfeld-Rieger syndrome resulting from mutation of the FKHL7 gene on chromosome 6p25. Eur J Hum Genet 2000; 8: 71-74.

10 Nishimura DY, Swiderski RE, Alward WL et al: The forkhead transcription factor gene FKHL7 is responsible for glaucoma phenotypes which map to 6p25. Nat Genet 1998; 19: 140-147.

11 Lehmann OJ, Ebenezer ND, Jordan $\mathrm{T}$ et al: Chromosomal duplication involving the forkhead transcription factor gene FOXC1 causes iris hypoplasia and glaucoma. Am J Hum Genet 2000; 67: 1129-1135.

12 Lehmann OJ, Ebenezer ND, Ekong R et al: Ocular developmental abnormalities and glaucoma associated with interstitial $6 \mathrm{p} 25$ duplications and deletions. Invest Ophthalmol Vis Sci 2002; 43: $1843-1849$.

13 Nishimura DY, Searby CC, Alward WL et al: A spectrum of FOXC1 mutations suggests gene dosage as a mechanism for developmental defects of the anterior chamber of the eye. Am J Hum Genet 2001; 68: 364-372.

14 Kleinjan DA, van Heyningen V: Long-range control of gene expression: emerging mechanisms and disruption in disease. $\mathrm{Am}$ J Hum Genet 2005; 76: 8-32.

15 Velagaleti GVN, Bien-Willner GA, Northup JK et al: Position effects due to chromosome breakpoints that map $\sim 900 \mathrm{~kb}$ upstream and $\sim 1.3 \mathrm{Mb}$ downstream of SOX9 in two patients with campomelic dysplasia. Am J Hum Genet 2005; 76: 652-662. 